Supporting information for

\title{
Synthesis of Colloidal Molecule from Soft Microgel Spheres
}

\author{
Qingping Yuan, Jianjun Gu, Ya-nan Zhao, Lijuan Yao, Ying Guan and Yongjun Zhang*
}

\section{Experimental details}

\section{Materials}

N-Isopropylacrylamide (NIPAM) was purchased from Tokyo Chemical Industry Co. Sodium dodecyl sulfate (SDS) and pluronic F108 were purchased from Sigma-Aldrich. $\mathrm{N}, \mathrm{N}^{\prime}$-methylenebis(acrylamide) (BIS) and 2,2-diethoxyacetophenone (DEAP) were purchased from Alfa Asear. Cysteamine was purchased from Aladdin. Ficoll 400 was purchased from Pharmacia. N-(3-Dimethylaminopropyl)-N'-ethylcarbodiimide hydrochloride (EDC), acrylic acid (AAc), potassium persulfate (KPS), and allylamine were purchased from Tianjin Chemical Reagent Company. NIPAM was purified by recrystallization from hexane/acetone mixture and dried in a vacuum prior to use. AAc was distilled under reduced pressure. Other reagents were used as received.

\section{Synthesis of PNIPAM microgels with surface carboxylic acid groups}

PNIPAM microgels were synthesized by free radical precipitation polymerization. Briefly, $\operatorname{NIPAM}(4.200 \mathrm{~g}), \mathrm{BIS}(0.072 \mathrm{~g})$ and SDS (0 or $0.087 \mathrm{~g}$ ) were dissolved in $290.00 \mathrm{~mL}$ of deionized water. The reaction mixture was transferred to a three-necked round-bottom flask equipped with a condenser and a nitrogen line. The solution was purged with nitrogen and heated to $70.0{ }^{\circ} \mathrm{C}$. After $1 \mathrm{~h}, 0.081 \mathrm{~g}$ of KPS (dissolved in $10.00 \mathrm{~mL}$ of deionized water) was added to initiate the reaction. The reaction was allowed to proceed for $3 \mathrm{~h}$, and then $0.101 \mathrm{~g}$ of AAc was added using an injector. The reaction was allowed to proceed for another $2 \mathrm{~h}$. The resultant microgels were purified by dialysis against water with frequent water change for 1 week. The microgels synthesized in the presence of SDS have a small size $\left(D_{h} \sim 310 \mathrm{~nm}\right.$ at $\left.25^{\circ} \mathrm{C}\right)$, while the microgels synthesized in the absence of SDS have a large size $\left(D_{h} \sim 800 \mathrm{~nm}\right.$ at $\left.25^{\circ} \mathrm{C}\right)$.

\section{Synthesis of vinyl- and thiol-modified PNIPAM microgels}

To $50.00 \mathrm{~mL}$ of purified PNIPAM microgel dispersion (small size or large size), $0.143 \mathrm{~g}$ of allylamine and $0.479 \mathrm{~g}$ of EDC were added. After being stirred at room temperature for $4 \mathrm{~h}$, the mixture was dialyzed against water with frequent water change for 3 days. The resulting product was named as vinyl-PNIPAM (small size or large size).

To $200.00 \mathrm{~mL}$ of purified PNIPAM microgel dispersion (small size or large size), $1.136 \mathrm{~g}$ of cysteamine and $1.919 \mathrm{~g}$ of EDC were added. After being stirred at room temperature for $4 \mathrm{~h}$, the mixture was dialyzed against water with frequent water change for 3 days. The resulting product was named as SH-PNIPAM (small size or large size).

\section{Preparation of Microgel Clusters}

Mixed dispersions of vinyl-PNIPAM and SH-PNIPAM were prepared by mixing the corresponding microgel dispersions at a ratio of 40:1. For large size microgels, the mixed 
dispersions were concentrated by centrifugation at $12000 \mathrm{rpm}$ and $10^{\circ} \mathrm{C}$ for $2 \mathrm{~h}$, followed by decanting the supernatant. To obtain concentrated dispersion of the small size microgels, the mixed dispersions were lyophilized. Then $0.800 \mathrm{~g}$ of the lyophilized microgels was re-dispersed in $19.200 \mathrm{~g}$ of deionized water.

To $10.0 \mathrm{~g}$ of concentrated mixed dispersion, $100 \mu \mathrm{L}$ of DEAP $(0.24 \mathrm{~mol} / \mathrm{L}$ in DMSO) was added. The dispersion was then injected into the space between two quartz slides separated by a rubber spacer. The samples were kept at room temperature to allow them to self-assemble into colloidal crystals. Finally the samples were irradiated with UV light for $1 \mathrm{~h}(\lambda=365 \mathrm{~nm})$.

To separate the particles, a linear gradient of ficoll $400(2.0-8.0 \mathrm{wt} \%)$ in $1.0 \% \mathrm{w} / \mathrm{w}$ pluronic F108/water solution was prepared. $1.00 \mathrm{~mL}$ of the dispersion was carefully loaded on top of the gradient and centrifuged for $10 \mathrm{~min}$ at $14000 \mathrm{rpm}$ and $15^{\circ} \mathrm{C}$. A syringe with pipetting needle was used to pull out individual bands from the sample. The fractions were purified by several centrifugation-redispersion cycles in deionized water.

\section{Characterizations}

Fourier transform infrared (FTIR) spectra were measured on a Bio-Rad FTS-6000 spectrometer using the conventional $\mathrm{KBr}$ pellet method. ${ }^{1} \mathrm{H}$ NMR spectra were recorded on a Varian UNITY-plus 400 NMR spectrometer using $\mathrm{D}_{2} \mathrm{O}$ or DMSO- $_{6}$ as solvent. The hydrodynamic diameter $\left(D_{h}\right)$ of the particles were measured by dynamic light scattering(DLS) with a Brookhaven 90Plus laser particle size analyzer using deionized water as solvent. All the measurements were carried out at a scattering angle of $90^{\circ}$. The sample temperature was controlled with a build-in Peltier temperature controller. Reflection spectra of the colloidal crystals were measured with an AvaSpec-2048 Fiber Optic spectrometer. Optical micrographs and confocal images were obtained on a Leica TCS SP8 Confocal Microscope. To acquire the confocal images of the clusters, Rhodamine $B$ was added to the dispersion before imaging. The final Rhodamine $B$ concentration is $\sim 1 \times 10^{-4} \mathrm{~mol} / \mathrm{L}$. The negatively charged particles were stained by the cationic dye due to the electrostatic interaction between them. Both the surface and the core of the particles were stained. SEM images were obtained on a JSM-7500F scanning electron microscope operating at $5 \mathrm{KV}$. The microgel dispersions were applied on silicon wafer and dried in the air. They were sputtered with gold before characterization. 
(A)
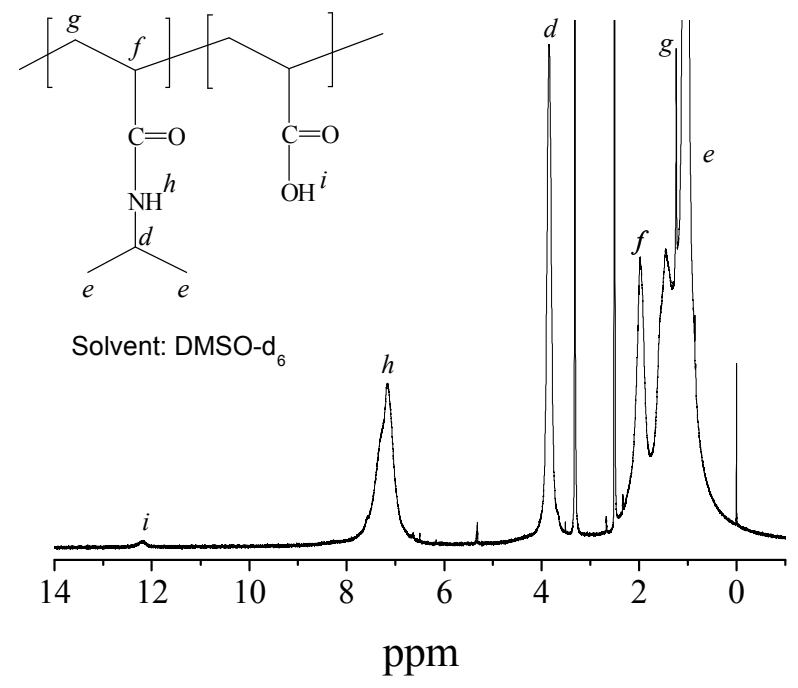

(B)

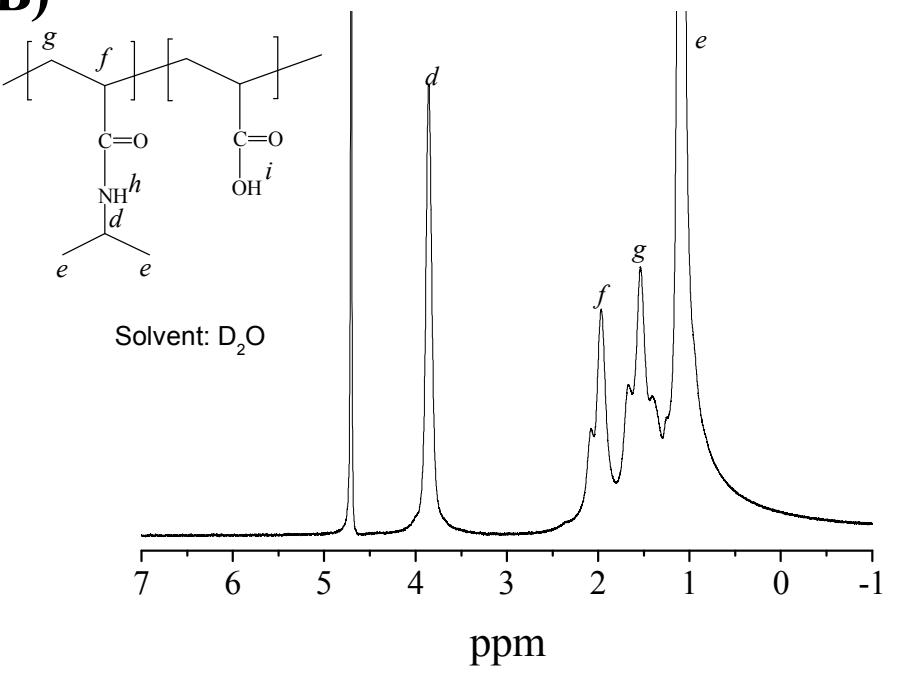




\section{(C)}
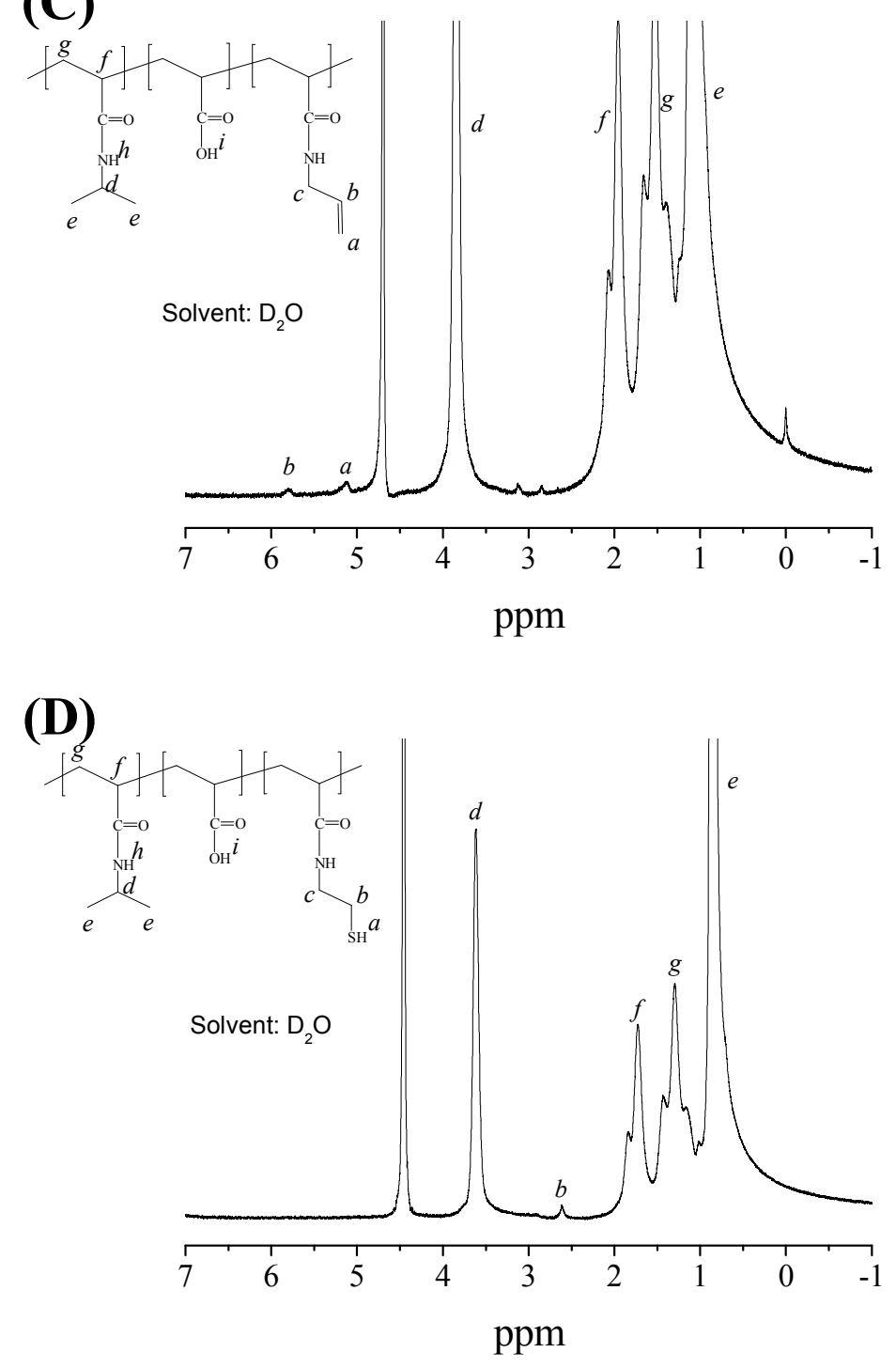

Figure S1. ${ }^{1} \mathrm{H}$ NMR spectra of the parent PNIPAM microgel,(A and $\left.B\right)$ the allylamine-modified microgel vinyl-PNIPAM, (C) and the cysteamine-modified microgel SH-PNIPAM.(D) The solvent is DMSO- $d_{6}$ for $A$ and $D_{2} O$ for $B, C$ and $D$, respectively. In DMSO- $d_{6}$ PNIPAM microgel presents a peak at $12.10 \mathrm{ppm}$ because of the surface carboxylic acid groups. Successful introduction of vinyl groups was confirmed by the appearance of new peaks at 5.80 and $5.12 \mathrm{ppm}(\mathrm{C})$. The appearance of a new peak at $2.61 \mathrm{ppm}\left(-\mathrm{NH}-\mathrm{CH}_{2}-\mathrm{CH}_{2}-\mathrm{S}-\right)$ confirms the successful coupling of cysteamine with the microgels (D). 


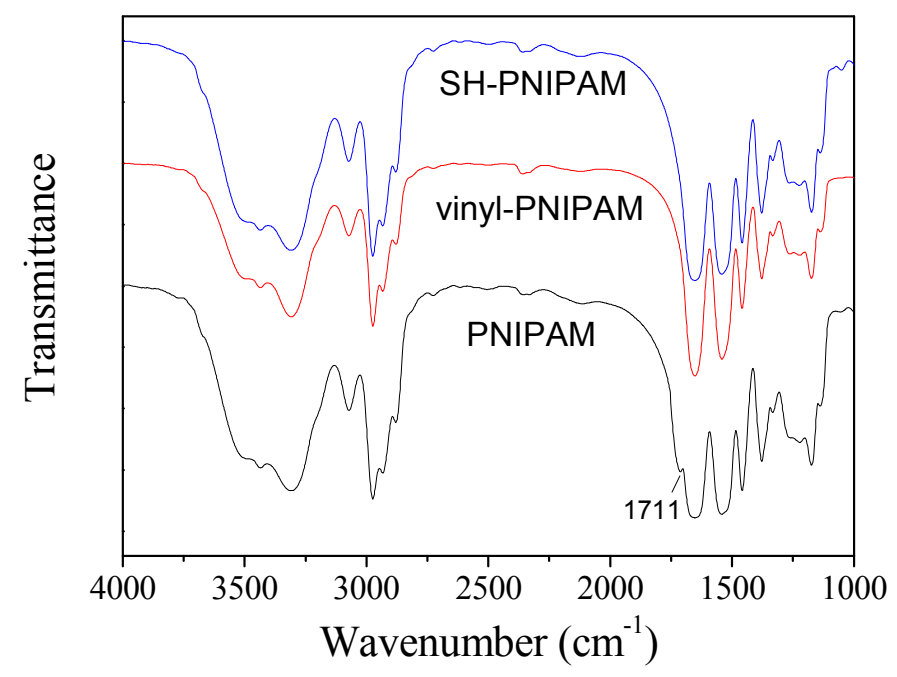

Figure S2. FTIR spectra of the parent PNIPAM microgel, the allylamine-modified microgel vinyl-PNIPAM, and the cysteamine-modified microgel SH-PNIPAM. PNIPAM microgel presents a peak at $1711 \mathrm{~cm}^{-1}$, which is assigned to the stretching of the surface carboxylic acid groups. The intensity of the peak decreases significantly after modification. 

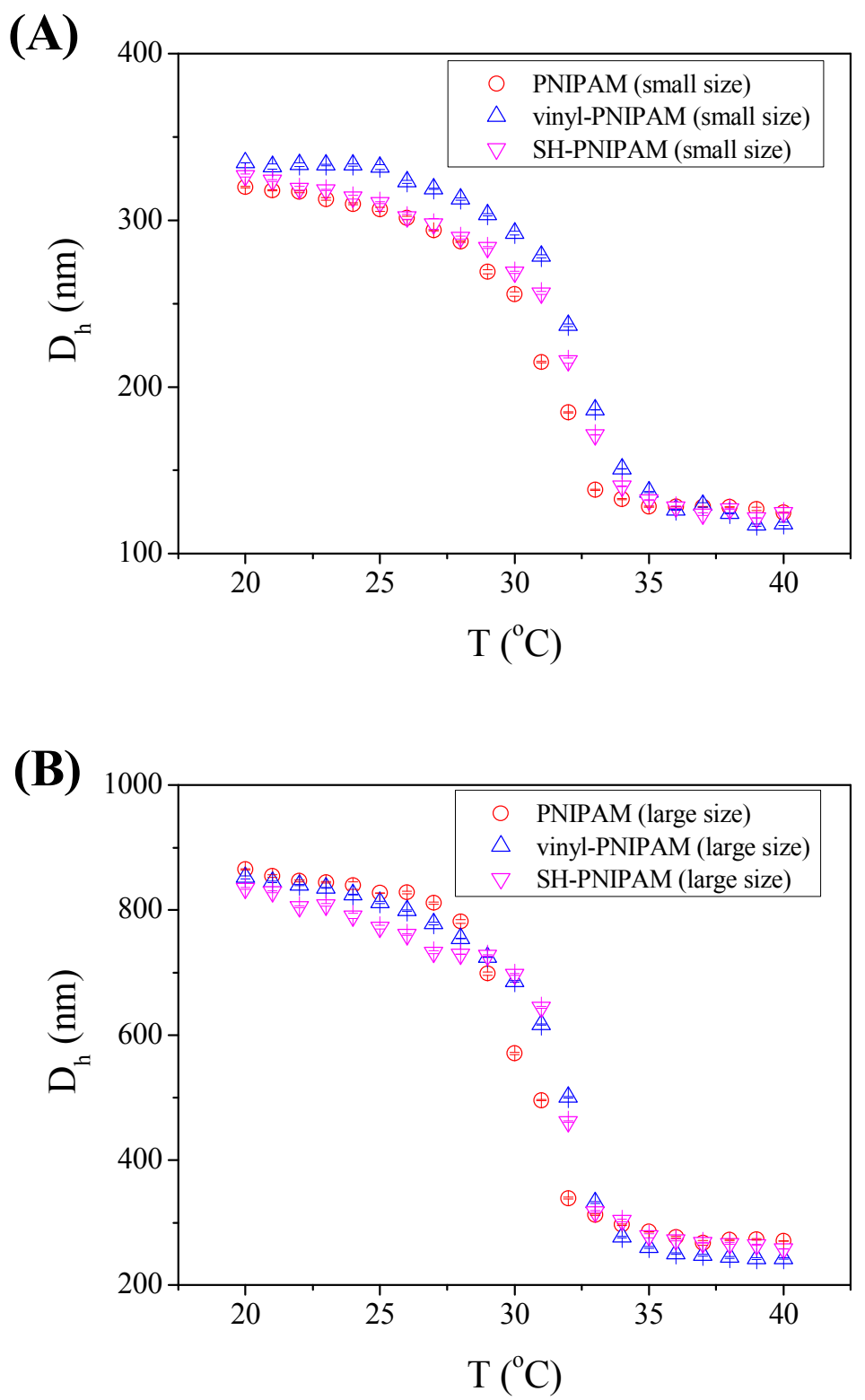

Figure S3. Hydrodynamic diameter $\left(D_{h}\right)$ of the microgel particles measured by dynamic light scattering as a function of temperature. (A) Small size PNIPAM and the corresponding vinyl-PNIPAM and SH-PNIPAM. $\left(D_{h}=\sim 310 \mathrm{~nm}\right.$ at $\left.25^{\circ} \mathrm{C}\right)$ (B) Large size PNIPAM and the corresponding vinyl-PNIPAM and SH-PNIPAM. $\left(D_{h}=\sim 800 \mathrm{~nm}\right.$ at $\left.25^{\circ} \mathrm{C}\right)$ 


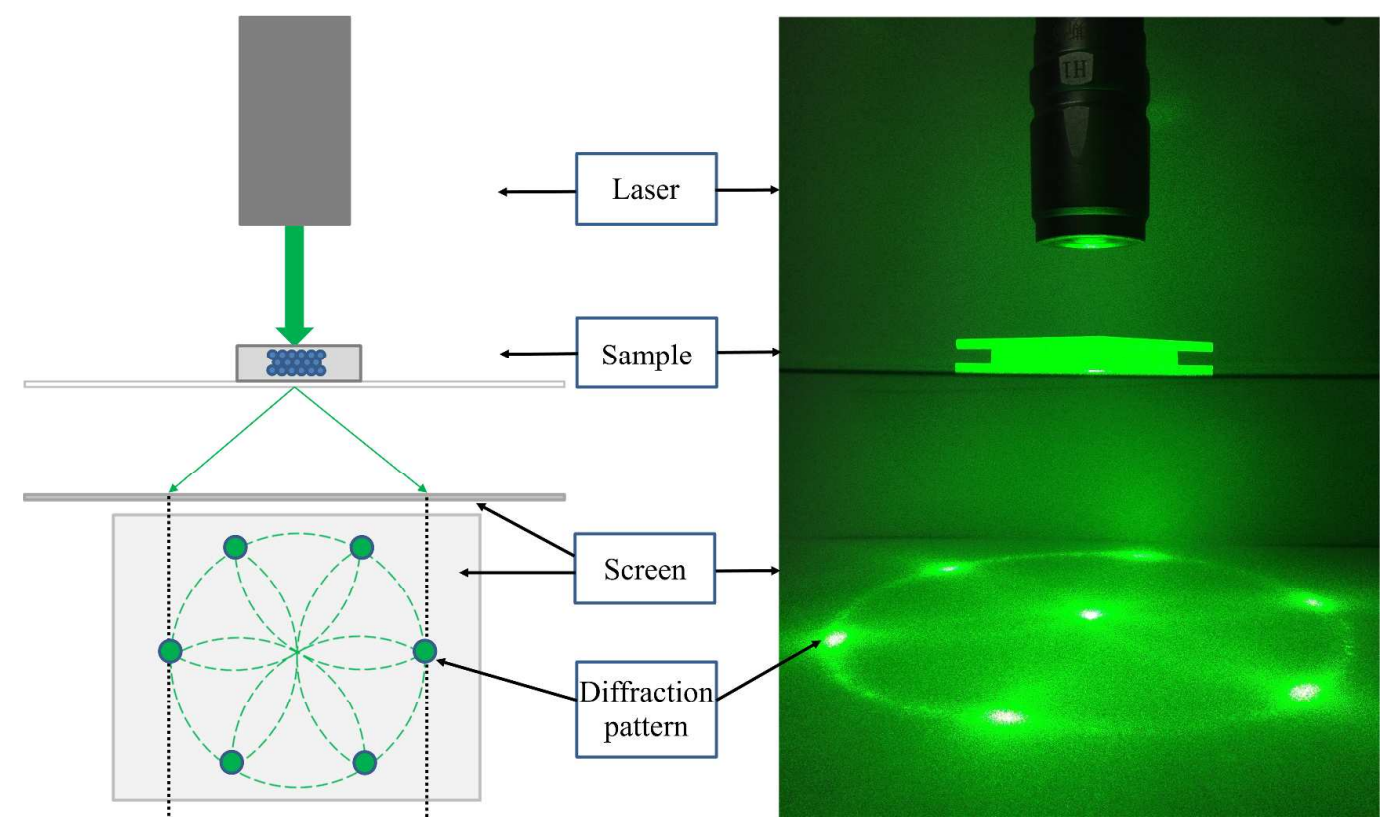

Figure S4. Schematic illustration (left) and photograph (right) of the experimental setup for the laser diffraction measurement. 
(A)

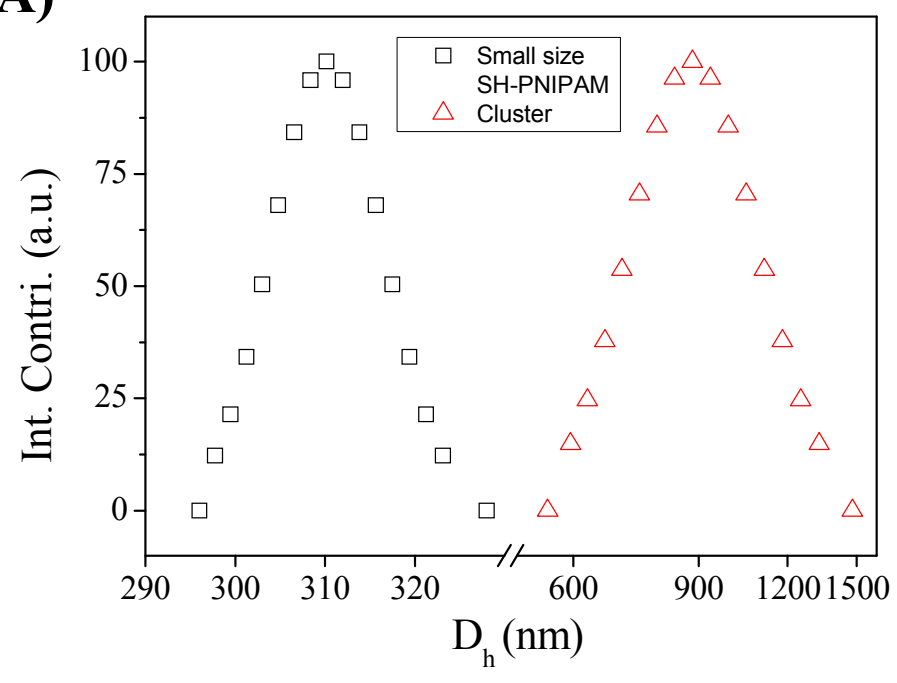

(B)

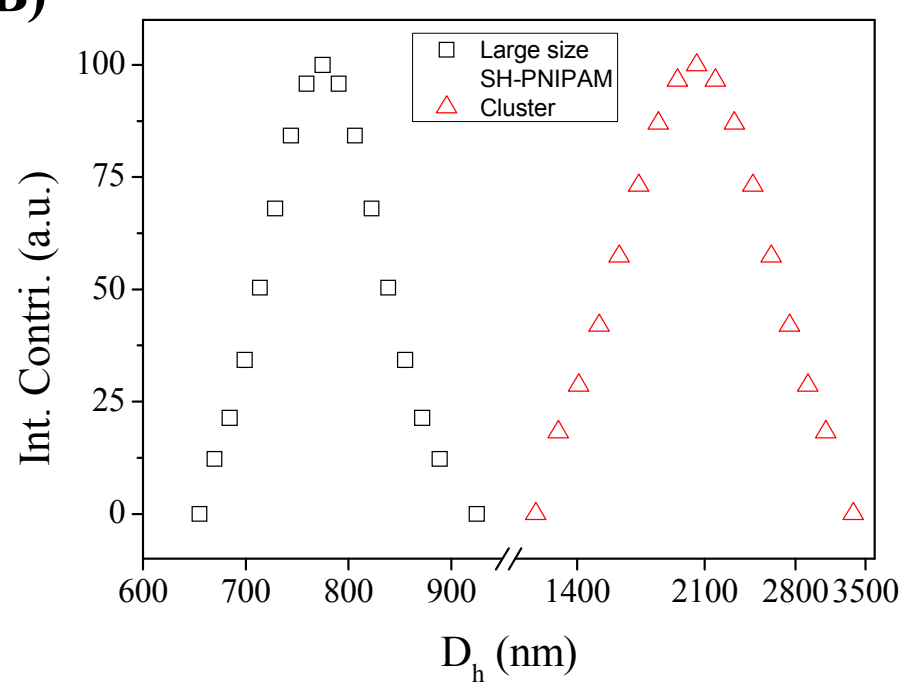

Figure S5. Size distributions of small size (A) and large size (B) SH-PNIPAM microgel and the corresponding cluster. $\mathrm{T}=25^{\circ} \mathrm{C}$. 


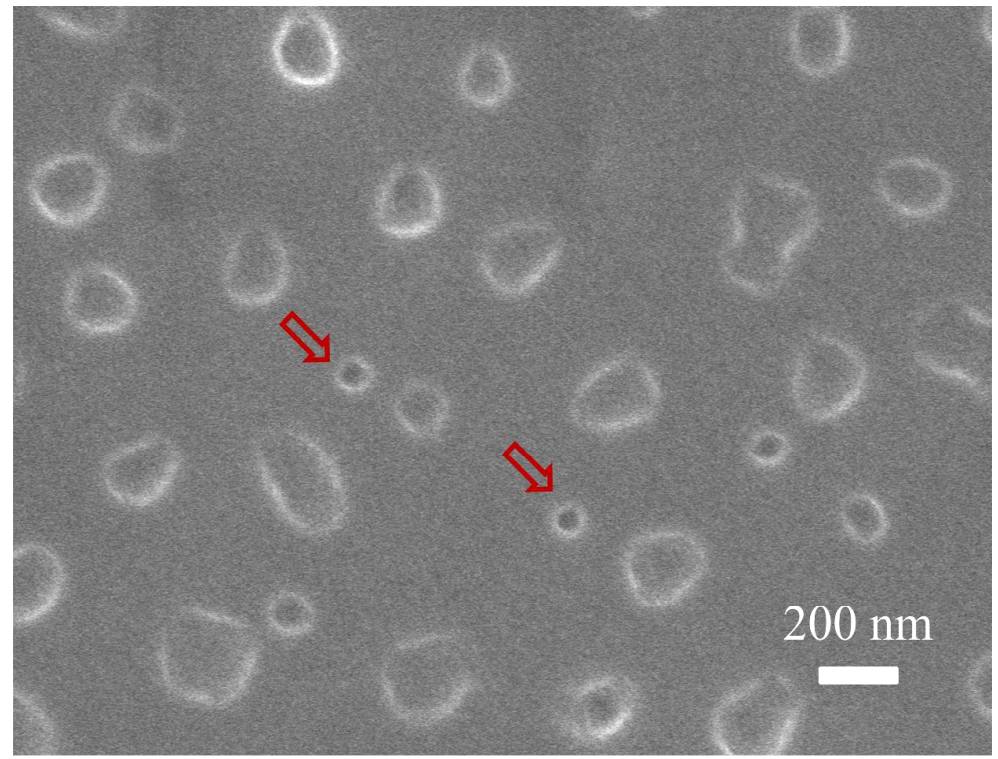

Figure S6. Scanning electron micrographs of clusters from small size microgels. The individual microgel spheres in the clusters cannot be identified. The arrows indicate some single microgel particles. 


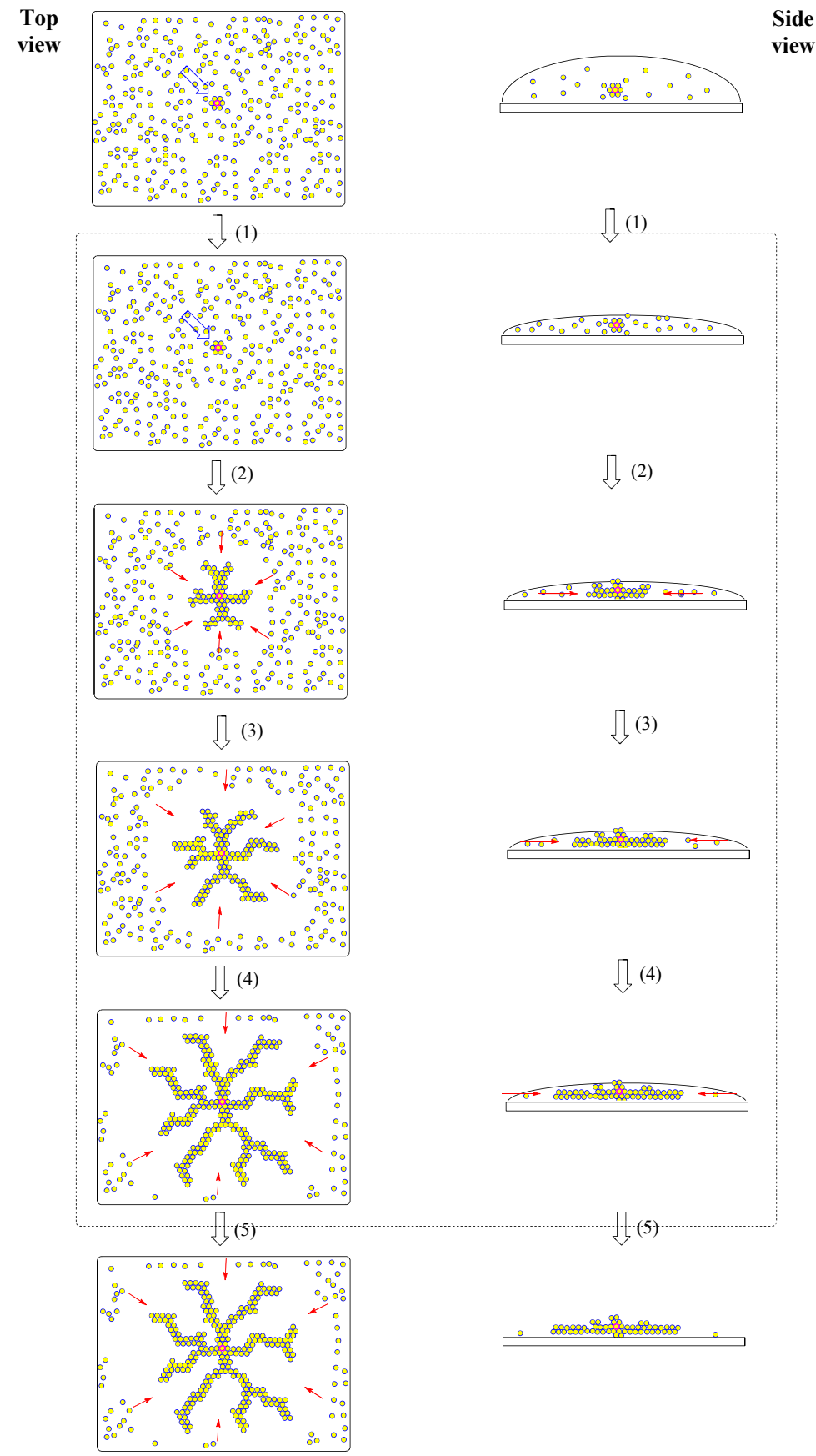

Figure S7. Schematic illustration of the formation of the dendritic structures shown in Figure 4. The left and right part is the top and side view of the microgel dispersion, respectively. (1) Concentration of the dispersion increases as a result of the water evaporation. (2)-(4) The microgel spheres diffuse and add to the microgel cluster. The crystalline structure of the microgel clusters makes them good nuclei for the addition of single microgel spheres. (Jungblut, S.; Dellago, C. Physical Review E 2013, 87, 012305.) The diffusion-limited aggregation of the microgel spheres results in a fractal dendritic structure.( Jr. Witten, T. A.; Sander, L. M. Physical Review Letters 1981, 47, 1400-1403.) (5) Complete evaporation of water leaves the dendritic structure. Collapse and deformation may occur but the dendritic structure remains. The drying process was depicted 
according to Horigome and Suzuki. (Horigome, K.; Suzuki, D. Langmuir 2012, 28, 12962-12970.)

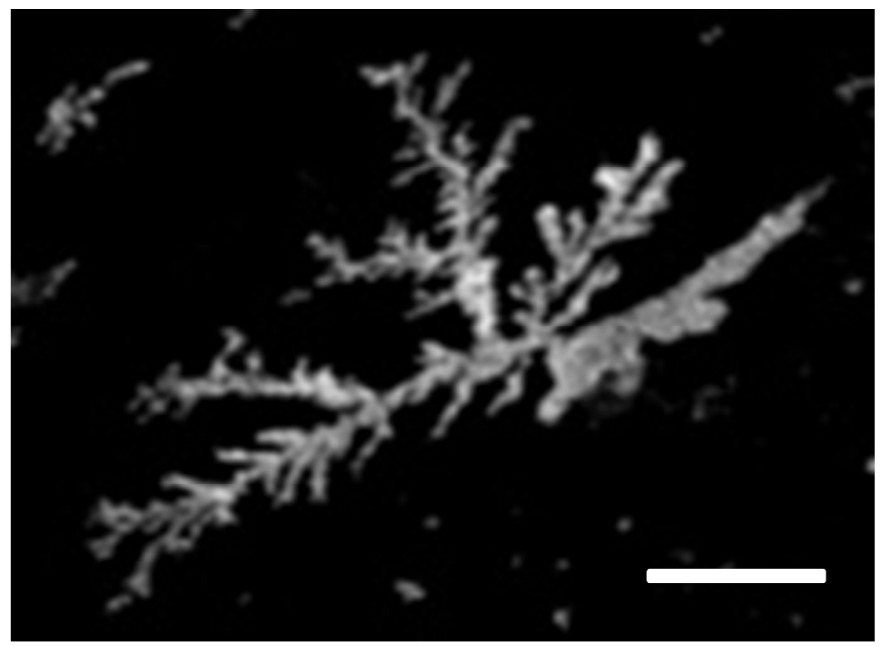

Figure 8. A zoomed-in view of the dendritic structure. Scale bar: $2 \mu \mathrm{m}$.

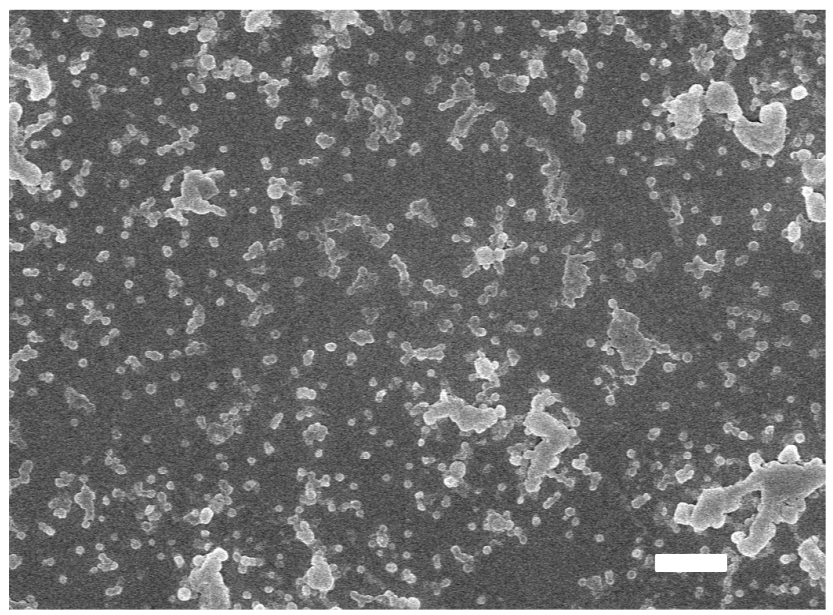

Figure 9. SEM image of a dispersion of small size PNIPAM microgel dried on silicon wafer. The dispersion is identical to the one shown in Figure 4. The only difference is that no microgel cluster was added. Scale bar: $1 \mu \mathrm{m}$. 